\section{Ocular sequelae of pneumatic drills}

\author{
Abstract \\ Purpose To determine the ocular sequelae of \\ rockdrilling. \\ Methods Nineteen rockdrillers and 20 age-, \\ sex- and race-matched control subjects \\ underwent ocular examination in a \\ prospective manner. \\ Results Subepithelial corneal opacities were \\ found in 12 drillers $(63 \%)$ and none of the \\ controls; pigmented trabecular meshwork was \\ noted in 13 drillers $(68 \%)$ and 1 control $(5 \%)$; \\ low-tension glaucoma was diagnosed in 1 \\ driller (5\%); vitreous liquefaction was present \\ in 17 of 17 drillers $(100 \%)$ examined by a retina \\ specialist and 9 of 20 controls (45\%). \\ Conclusions The sequelae of drilling include \\ corneal scars from projectile pieces of drilled \\ stone as well as vibration-induced pigment \\ deposition in the trabecular meshwork and \\ vitreous liquefaction. Wearing of safety \\ glasses is recommended.
}

Key words Corneal scar, Low-tension glaucoma, Pigmented trabecular meshwork, Rockdrill, Vitreous liquefaction

Little is known about the ocular hazards of operating a pneumatic drill. Pneumatic rock drills are used in the stone industry by quarrymen and stone carvers or as road breakers. Lebanon is witnessing a major postwar reconstruction of infrastructure including water supply, sewage disposal, electricity, telecommunication and highways. It has become customary to hear the rockdrills at work at most street corners. The ocular findings in pneumatic drill operators were analysed.

S.H. Uwaydat

A.S. Khouri

Department of

Ophthalmology

American University of

Beirut

Beirut, Lebanon

\section{A. Mansour, MD \\ Department of \\ Ophthalmology \\ American University of \\ Beirut \\ Beirut, Lebanon \\ Tel: +9611348543 \\ Fax: +9611744464}

Received: 11 May 1999 Accepted in revised form: 13 September 1999
AHMAD M. MANSOUR, SAMI H. UWAYDAT, ALBERT S. KHOURI

Controls consisted of workers recruited from their place of work who had comparable socioeconomic class to the rockdrillers.

\section{Results}

There were 19 white male drillers with a mean age of 29.4 years, and 20 white male controls with a mean age of 25.4 years. The mean duration of work as a driller was 3.2 years with an average working day of $5.8 \mathrm{~h}$. Back pain was experienced in 6 drillers. Three drillers experienced one of the following: wrist pain, paresthaesia of the right upper extremity and paresthaesia of the right lower extremity.

Uncorrected visual acuities were equal or better than $6 / 7.5(20 / 25)$ in both groups. Intraocular pressures were comparable between the two groups and were below $20 \mathrm{mmHg}$. Multiple small round or linear subepithelial corneal opacities were present in 12 drillers (17 eyes), being bilateral in 5 and unilateral in 7 . Corneal opacities involved the left eye in 12 drillers and the right eye in 5 drillers. The mean number of corneal scars was 1.8 per affected eye. Corneal opacities were absent in the control group $(p<0.001)$.

The trabecular meshwork was bilaterally pigmented in 13 drillers with neither iris transillumination defects nor retrocorneal pigment deposition. Two drillers had fine pigment deposits on the anterior lens surface, and a third driller had focal defects in the iris sphincter by transillumination. Four drillers had fine bilateral scattered peripheral anterior synechiae. Pigmented trabecular meshwork and peripheral anterior synechiae were found bilaterally in one control each $(p<0.001)$. All subjects from either group had grades 3 to 4 open angle. ${ }^{1}$ One driller had previously undiagnosed low-tension glaucoma with a cupdisc ratio of 0.75 and Bjerrum scotoma bilaterally. The latter subject had a negative history for migraine, Raynaud's phenomenon, systemic hypotension or cold extremities. During our field survey, two site engineers volunteered the information that when they operated the drill on a few occasions, they experienced photopsias at night.

Seventeen drillers and 20 controls underwent detailed vitreous examination by the same retinal specialist. Posterior vitreous detachment with a Weiss ring was noted in both eyes of one 
driller and none of the controls. Vitreous liquefaction mimicking posterior vitreous detachment ${ }^{2-4}$ was noted in 32 eyes of 16 drillers and 18 eyes of 9 controls $(p<0.01)$. Formed vitreous was present in 11 controls bilaterally and in none of the drillers $(p<0.001)$. Retinal pathology was present in the control group only, and included peripheral retinoschisis in 2 eyes of one subject, lattice degeneration and atrophic holes in 6 eyes, and a large retinitis scar from presumed toxoplasmosis in 1 eye.

\section{Discussion}

The pneumatic drill contains a steel tube firmly mounted on a rigid base plate to prevent the tool from jumping and filled with balls of hardened steel to act as an energy absorber. Despite the shock absorber unit, the acceleration of the handles results in vibrations. Systemic sequelae of drilling can be divided into peripheral neuropathy, musculoskeletal abnormalities and peripheral circulatory disorders. ${ }^{5-11}$ The white finger syndrome is characterised by numbness and tingling of the fingertips, as well as spasmodic blanching of the digits in response to cold. This vasospastic disorder is caused by long-term exposure to vibration and can be reversible. ${ }^{11}$ Acute exposure to driller vibration in volunteers causes a generalised increase in the sympathetic tone of the extremities. ${ }^{8}$ Habitual exposure to vibration leads to sustained increase in the sympathetic tone resulting in the white finger syndrome. ${ }^{8}$ Peripheral neuropathy can occur with minor vibratory tools previously thought harmless, such as used by dental hygienists or dentists, ${ }^{12}$ autopsy assistants ${ }^{13}$ and assistants who harvest bone for bone banks. $^{14}$

The ocular sequelae of operating a pneumatic drill have not previously been studied and include corneal scars from small projectile pieces of drilled stone hitting the cornea, and vibration-induced vitreous liquefaction and pigmented trabecular meshwork. Physical exercise can induce a shower of pigment into the anterior chamber in subjects with the pigmentary dispersion syndrome. ${ }^{15,16}$ Pigment shedding in drillers is speculated to result either from a vibration injury to the iris pigment epithelium, or from vibration-induced iridozonular touch. Iris pigment can block the flow of aqueous humour through the outflow channels. ${ }^{17}$ Long-term follow-up of drillers is needed to assess the late sequelae of vibration on the intraocular pressure. Low-tension glaucoma may be coincidental or it may be related to drilling-induced ocular vasospasm ${ }^{18,19}$ similar to vibration-related Raynaud's phenomenon. ${ }^{6}$ Two engineers experienced photopsias after a brief episode of jackhammering, raising the possibility of an induced retinal vasospasm.

Several researchers have emphasised the difficulty in distinguishing posterior vitreous detachment from a zone of posterior vitreous liquefaction with residual attached posterior cortical vitreous. ${ }^{2-4}$ The diagnosis of posterior vitreous detachment is certain when the posterior cortical vitreous contains the vitreous condensation ring over the optic nerve (Weiss ring) or an operculum. Otherwise, the diagnosis of 'pseudodetachment of the posterior vitreous' ${ }^{3}$ or 'vitreoschisis ${ }^{2}$ is made, denoting liquefaction with cavitation in the posterior vitreous and with persistent attachment of the posterior cortex to the internal limiting lamina. Vitreous liquefaction is an aging process starting in childhood and adolescence and increasing with age. ${ }^{20}$ The mechanism of vitreous liquefaction is poorly understood. The interaction between collagen and hyaluronic acid is dependent upon the conformational state of each macromolecule and a change in the conformation of hyaluronic acid molecules could result in vitreous liquefaction. ${ }^{20}$ It is speculated that vibration could trigger a dissociation of the collagen hyaluronic acid molecules ultimately leading to synchisis.

Three main factors are involved in posterior vitreous detachment: ${ }^{20-22}$ vitreous liquefaction, gel shrinkage and loosening of vitreoretinal adhesion. Posterior vitreous detachment occurs with increasing age, high myopia and blunt trauma. Foos ${ }^{21}$ detected posterior vitreous detachment in $17 \%, 51 \%$ and $53 \%$ of autopsy eyes in the seventh, eighth and ninth decade, respectively. Sebag ${ }^{22}$ found in young subjects a very strong adherence of the internal limiting lamina to the vitreous cortex over the posterior pole. It seems that the low incidence of posterior vitreous detachment in the present drillers could be related to their young age and to the strong adhesion of the internal limiting lamina to the posterior cortex. It is unknown whether drilling could induce a posterior vitreous detachment in older workers.

The following recommendations are given to drillers: (1) decrease the amount of daily work to less than $4 \mathrm{~h},{ }^{11,23,24}$ (2) use anti-vibratory gloves, ${ }^{25}$ (3) have yearly medical and ocular examinations and (4) wear safety goggles.

\section{References}

1. Scheie HG. Width and pigmentation of the angle of the anterior chamber. Arch Ophthalmol 1957;58:510-3.

2. Balazs EA. The vitreous. Int Ophthalmol Clin 1973;13:169-87.

3. Jaffe NS. The vitreous in clinical ophthalmology. St Louis: CV Mosby, 1969:83-98.

4. Gass JDM. Idiopathic senile macular hole: its early stages and pathogenesis. Arch Ophthalmol 1988;106:629-39.

5. Blann AD, Allen J, McKenna K, Wilder D, Pope MH, Kaigle $\mathrm{AM}$, et al. Vibration and induction of endothelial injury. Lancet 1992;340:616-7.

6. Hachulla E, Devulder B. Calcium antagonists and Raynaud's phenomenon. Therapie 1993;48:707-11.

7. Lundborg G, Dahlin LB, Lundstrom R, Neckling LE, Stromberg T. Vibrotactile function of the hand in compression and vibration-induced neuropathy: sensibility index - a new measure. Scand J Plast Reconstr Surg Hand Surg 1992;26:275-9.

8. Egan CE, Espie BH, McGrann S, McKenna KM, Allen JA. Acute effects of vibration on peripheral blood flow in healthy subjects. Occup Environ Med 1996;53:663-9.

9. Kaji H, Honma H, Usui M, Yasuno Y, Saito K. Hypothenar hammer syndrome in workers occupationally exposed to vibrating tools. J Hand Surg [Br] 1993;18:761-6. 
10. Lau CS, O'Dowd A, Belch JJ. White cell activation in Raynaud's phenomenon of systemic sclerosis and vibration induced white finger syndrome. Ann Rheum Dis 1992;51:249-52.

11. Bovenzi M. Hand-arm vibration syndrome and doseresponse relation for vibration induced white finger among quarry drillers and stonecarvers. Italian Study Group on Physical Hazards in the Stone Industry. Occup Environ Med 1994;51:603-11.

12. Akesson I, Lundborg G, Horstmann V, Skerfving S. Neuropathy in female dental personnel exposed to high frequency vibrations. Occup Environ Med 1995;52:116-23.

13. Toren $K$, Jonsson $P$. Is skull sawing by autopsy assistants overlooked as a cause of vibration-induced white fingers? Scand J Work Environ Health 1996;22:227-9.

14. Cherniack MG, Mohr S. Raynaud's phenomenon associated with the use of pneumatically powered surgical instruments. J Hand Surg [Am] 1994;19:1008-15.

15. Smith DL, Kae SF, Rabbani BS, Musch DC. The effects of exercise on intraocular pressure in pigmentary glaucoma patients. Ophthalmic Surg 1989;20:561-7.

16. Schenker HI, Luntz MH, Kels B, Podos SM. Exercise-induced increase of intraocular pressure in the pigmentary dispersion syndrome. Am J Ophthalmol 1980;89:598-600.
17. Grant WM. Experimental aqueous perfusion in enucleated human eyes. Arch Ophthalmol 1963;69:783-801.

18. Goldberg I, Chai E, Chia A, Benscher C, Bauman A, Chen J. The Hettinger band vibration test, vasospasm, and glaucoma. Surv Ophthalmol 1999;43:S66-78.

19. Chai E, Goldberg I, Chia A, Chen J. Visual field responses to a hand vibration stimulus. Surv Ophthalmol 1999;43:S79-86.

20. Sebag J. Ageing of the vitreous. Eye 1987;1:254-62.

21. Foos RY. Posterior vitreous detachment. Trans Am Acad Ophthalmol Otol 1972;76:480-97.

22. Sebag J. Age-related differences in the human vitreoretinal interface. Arch Ophthalmol 1991;109:966-71.

23. Mirbod SM, Yoshida H, Komura Y, Fujita S, Nagata C, Miyashita $\mathrm{K}$, et al. Prevalence of Raynaud's phenomenon in different groups of workers operating hand-held vibrating tools. Int Arch Occup Environ Health 1994;66:13-22.

24. Stromberg T, Dahlin LB, Lundborg G. Hand problems in 100 vibration-exposed symptomatic male workers. J Hand Surg [Br] 1996;21:315-9.

25. Reynolds D, Weaver D, Jetzer T. Application of a new technology to the design of effective anti-vibration gloves. Cent Eur J Public Health 1996;4:140-4. 